\title{
An Insight into Research and Studies on Enhanced Oil Recovery (EOR) In Petroleum Industries
}

\author{
Sunil Jayant Kulkarni \\ Datta Meghe College of Engineering, Airoli, Navi Mumbai, \\ Maharashtra, India
}

\begin{abstract}
The petroleum industry is backbone of any countries economy. The oil exploration and consumption is many time deciding factor for growth. Various aspects such as catalyst cracking, sludge handling, gas recovery are widely investigated and studied. Efficient oil exploration is very important in petroleum and refining industry. The increased cost and depleting resources call for enhanced oil recovery. Enhanced oil recovery (EOR) methods are used after secondary or primary recovery methods. Gases or liquids are injected to mobilize the residual amount of oil. Microbial enhanced oil recovery (MEOR) is well proven technology for enhanced oil recovery. These enhanced oil recovery methods are classified as thermal methods, chemical methods, miscible/immiscible gas injection methods and other methods.
\end{abstract}

Keywords: Synergies, recovery, advancements, accumulation, mechanism.

\section{INTRODUCTION}

The available stocks for fossil fuels are depleting day by day. There is need to conserve the available feed stocks and use them with caution. In chemical process intensification, various techniques are being tried such as cavitation, hydrotropism, biocatalysts, fuel cells and membrane bioreactors [1-5]. Pinch analysis of heat exchanger networks also helps in saving energy [6-8]. Various alternate sources of energy include solar, tidal and wind energy $[9,10]$. These alternatives are environment friendly but having high installation cost. There is need for awareness about these non-conventional energy sources. The initial installation cost is high but not disadvantage is longer run. The petroleum industry is backbone of any countries economy. The oil exploration and consumption is many time deciding factor for growth. Various aspects such as catalyst cracking, sludge handling, gas recovery are widely investigated and studied. Efficient oil exploration very important in petroleum and refining industry. The increased cost and depleting resources call for enhanced oil recovery. The current review summarizes research and studies on enhanced oil recovery.

\section{AN INSIGHT INTO RESEARCH AND STUDIES ON ENHANCED OIL RECOVERY (EOR)}

Many time surface tension and viscosity become important factors in oil exploration. Small portion of oil, many times is not recovered due to these factors. Vesna et.al. presented factors affecting the recovery of this residual oil[11]. These enhanced oil recovery (EOR) methods are used after secondary or primary recovery methods. Gases or liquids are injected to mobilize the residual amount of oil. These enhanced oil recovery methods are classified as thermal methods, chemical methods, miscible/immiscible gas injection methods and other methods. They used price of crude at world market as a basis for their studies and justifying application of new technologies. Normally in primary recovery sections pumps and gas lifting are involved. In secondary recovery, either a natural gas flooding or water flooding are used to maintain pressure. According to Alagorni et.al., many methods such as water alternating gas (WAG) or simultaneous water alternating gas(SWAG) are being implemented [12]. These methods, according to him, have still some problems encountered by EOR engineers. They used nitrogen injection as one of the enhanced oil recovery methods. Nitrogen, according to him had many advantages such as availability, its noncorrosive, inert gas, friendly to environment, less compressible than $\mathrm{CO}_{2}$. In addition, it can vaporize the lighter components of crude oil. Moreover addition nitrogen can provide a gas drive.

Romero-Zeron discussed advancements in enhanced oil recovery processes [13]. He pointed out at renewed interest on research and development of EOR processes. According to him, significant 
volumes of oil accumulations can be targeted by using these advanced oil recovery methods. A synergistic approach among EOR processes can be a great help in achieving EOR targets. Synergies should be maintained among various approaches such as improved reservoir characterization, formation evaluation, reservoir modeling and simulation, reservoir management, well technology, new and advanced surveillance methods, production methods, and surface facilities. Kumar and Singh studied thermal pyrolysis for recovery of hydrocarbon liquid from waste high density polyethylene [14]. This method can convert can convert waste plastics into hydrocarbons. They chose waste high-density polyethylene (HDPE) plastic as the material for pyrolysis. In their investigation they optimized the liquid product yield at a temperature range of $400^{\circ} \mathrm{C}$ to $550^{\circ} \mathrm{C}$. They observed that the major product of the pyrolysis was oily liquid below 450 degree Celsius. They also found that, with the residence time for waste HDPE, the yield of the liquid fraction obtained increased. Their study and analysis also indicated the presence of a mixture of different fuel fractions such as gasoline, kerosene and diesel in the oil.

Banerjee et.al. carried out review on a green colonial microalga as a source of hydrocarbon [15]. 75\% of the dry mass of B. braunii is hydrocarbon. They reviewed production of hydrocarbons and other compounds by the alga. The feed stocks can be prepared from B. braunii by converting simple inorganic compounds and sunlight into feedstock products. They concluded that these kind of alternatives can be explored to reduce our dependence on fossil fuels. Davies et.al. carried out an investigation on recovery of hydrocarbons with emphasis on induced seismicity and hydraulic fracturing [16]. In their work, they published examples of induced earthquake, reactivation of faults and resultant seismicity. They proposed fluid pulse pathways including steps like directly from the wellbore, through new stimulated hydraulic fractures, through pre-existing fractures and minor faults and through the pore network of permeable beds or along bedding planes. According to them, compared to other anthropogenic triggers, hydraulic fracturing has been a relatively benign mechanism. Low volumes of fluid and short pumping times were a relatively benign mechanism. Gudina et.al. carried out an investigation on enhance oil recovery in laboratory sand-pack columns[17].In their studies, they tried to retrieve the oil from mature reservoirs. In their investigation, they used three Bacillus subtilis strains isolated from crude oil samples and four different hydrocarbon mixtures. They found that the additional oil recoveries ranged from 6 to $24 \%$. An investigation was carried out by Berglund and Petersson on refueling with and without vapour recovery for hydrocarbon fuels [18]. They found that the vapour recovery was able to eliminate 99 percent of the exposure during refueling. It also eliminated 95 percent of emissions to air. They used thermal desorption and capillary gas chromatography for sampling on an adsorbent tube. They separated major hydrocarbons on a methyl silicone phase.

Rudd and Hill studied measures to reduce emissions of VOCs during loading and unloading of ships [19]. According to their estimates VOC emissions from the loading of petroleum product are 0.07 percent of total VOC emission. Crude loading, according to them contributes 0.8 percent of total VOC. Ship driven activities such as loading, unloading, ballasting and transportation contributes to VOC. According to them, methods such as reducing volatility, vapour balancing, thermal oxidation, absorption, adsorption, membrane separation and cryogenic condensation can be used to control VOC. Shrimali reviewed various oil recovery technologies [20]. According to him, with decline in oil discoveries, the importance of enhanced oil recovery techniques is increasing. They reviewed research and investigation on enhanced oil recovery. According to these studies, microbial enhanced oil recovery (MEOR) is well proven technology for enhanced oil recovery. Still for this method to become acceptable and popular, extensive research is required. In order to find suitable microbe, understand their growth requirements and production conditions, more investigations are envisaged. It is also envisaged to optimize the operating conditions.

\section{Conclusion}

There is need to conserve the available feed stocks and use them with caution. In chemical process intensification various techniques are being tried such as cavitation, hydrotropism, biocatalysts, fuel cells and membrane bioreactors. Pinch analysis of heat exchanger networks also helps in saving energy. Various alternate sources of energy include solar, tidal and wind energy. These alternatives are environment friendly but are having high installation cost. There is need for awareness about these non-conventional energy sources.

Microbial enhanced oil recovery (MEOR) is well proven technology for enhanced oil recovery. Nitrogen injection is one of the effective enhanced oil recovery methods. According to the studies by 
researcher, a synergistic approach among EOR processes can be a great help in achieving EOR targets. It was pointed out that synergies should be maintained among various approaches such as improved reservoir characterization, formation evaluation, reservoir modeling and simulation, reservoir management, well technology, new and advanced surveillance methods, production methods, and surface facilities.

\section{REFERENCES}

[1] Sunil J. Kulkarni, 2016, "A Review on Studies and Research on Fuel Cells", International Journal of Research and Review, 3(1), PP.77-80

[2] Sunil J. Kulkarni, Ajaygiri K. Goswami, 2014,"Applications and Advancements in Treatment of Waste Water by Membrane Technology- A Review", International Journal Of Engineering Sciences \& Research Technology, 3(9), PP.446-449.

[3] Jain Jyoti, DubeyAlka and Singh Jitendra Kumar, 2013, "Application of Membrane-Bioreactor in Wastewater Treatment: A Review", International Journal of Chemistry and Chemical Engineering, 3(2), PP.115-122.

[4] Sunil Jayant Kulkarni, 2016, "A Review On Research And Studies On Kinetics Of Biological Reactions With Emphasis On Substrate Utilization”, Int. J Res Rev., 3(9), pp.12-15.

[5] Sunil Jayant Kulkarni, Ajaygiri Kamalgiri Goswami, 2014,"Research on Application of Hydrotropy: A Review", International Journal of Science, Engineering and Technology Research, 3(10), PP. 2617-2619.

[6] Y. P. Bhalerao, S. V. Patil, P. V. Vijay Babu, and S. J. Kulkarni, 2011, "Energy Retrofit Studies in Diethyl Thiophosphoryl Chloride (DETC) Plant", International Journal of Chemical Engineering and Applications, 2(6), PP.439-443.

[7] Murugesan M.P. and Balasubramani R., 2013, "The Experimental Study on Enhanced heat Transfer Performance in Plate Type Heat Exchanger", Research Journal of Engineering Sciences, 2(2), PP.1622.

[8] Sunil Jayant Kulkarni, Pallavi M.Kherde, 2015, "A review on studies and research onheatrecovery, regeneration and cogeneration”, Int. J Res Rev., 2(9), PP.584-589.

[9] Sunil Jayant Kulkarni, 2015, “Tidal Energy: A Review”, International Journal of Research,2(1), PP.55-58.

[10] Sunil Jayant Kulkarni, 2014, "Solar Distillation: A Review", International Journal of Research, 1(11), PP.1171-1176.

[11] Karovic Maricic Vesna, Lekovic Branko, Danilovic Dusan, 2014, "Factors Influencing Successful Implementation Of Enhanced Oil Recovery Projects", Underground Mining Engineering, 25, PP. 41-50.

[12] Abubaker H. Alagorni, Zulkefli Bin Yaacob, and Abdurahman H. Nour, 2015, "An Overview of Oil Production Stages: Enhanced Oil Recovery Techniques and Nitrogen Injection", International Journal of Environmental Science and Development, 6(9), PP.693-702.

[13] Laura Romero-Zeron, 2012, "Advances in Enhanced Oil Recovery Processes", www.intechopen.com, 1, PP.3-44.

[14] Sachin Kumar and R. K. Singh, 2011, "Recovery Of Hydrocarbon Liquid From Waste High Density Polyethylene By Thermal Pyrolysis", Brazilian Journal of Chemical Engineering, 28(4), pp. $659-667$.

[15] Anirban Banerjee, Rohit Sharma, Yusuf Chisti, and U. C. Banerjee, 2002,"Botryococcus braunii: A Renewable Source of Hydrocarbons and Other Chemicals", Critical Reviews in Biotechnology, 22(3), PP.245-279.

[16] Richard Davies, Gillian Foulger, Annette Bindley, Peter Styles, 2013, "Induced seismicity and hydraulic fracturing for the recovery of Hydrocarbons", Marine and Petroleum Geology, 45, PP. 171-185.

[17] Eduardo J. Gudina, Jorge F.B. Pereir, Rita Costa, Joao A.P. Coutinho,Jose. Teixeir, Lígia R. Rodrigues,2013,"Biosurfactant-producing and oil-degrading Bacillus subtilis strainsenhance oil recovery in laboratory sand-pack columns", Journal of Hazardous Materials, 261,PP. 106- 113.

[18] Pia M. Berglund and Göran Petersson, 1990,"Hazardous petrol hydrocarbons from refueling with and without vapour recovery", Sci. Total Environ., 91, PP.49-57. 
[19] Howard J Rudd and Nikolas A Hill, 2001,"Measures to Reduce Emissions of VOCs during Loading and Unloading of Ships in the EU", AEA Technology Environment, AEAT/ENV/R/0469, 2,PP.1-80.

[20] Hardikkumar V. Shrimali, 2015,"Developments in Enhanced Oil Recovery Technologies-A Review", International Journal of Research in Advent Technology, 3(6), PP.1-6.

\section{AUTHOR's BIOGRAPHY}

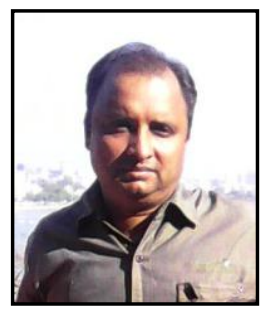

Mr. Sunil J. Kulkarni, has completed his Masters in Chemical Engineering from TatyasahebKore Institute of Engineering and Technology, Warananagar in 2006. $\mathrm{He}$ is currently pursuing his $\mathrm{phD}$ in chemical engineering. He is working as Assistant Professor in Chemical Engineering Department of Datta Meghe College of Engineering, Airoli, Navi Mumbai, India. The author has 16 years of experience in teaching and research. He has published 200 international review and research papers and presented 15 research papers in international conferences. His area of research includes adsorption, environmental engineering and catalysis. He is editorial board member of more than 25 international journals and reviewed many international papers. 